\title{
THE CONJOINT PSYCHOTHERAPY OF MARRIAGE PARTNERS*
}

\author{
ANDREW S. WATSON, M.D. \\ Department of Psychialry, University of Michigan, Ann Arbor, Michigan
}

After stating the premises about the marriage relationship, the strategic and practical goals of a conjoint treatment are described. Dynamics of transference-countertransference are conceptualized, and techniques of interpretation set forth. The advantages of having primary data about the marriage, speed in dealing with critical issues, economy of therapist's time and patient's resources, and the therapeutic leverage afforded by the method provide exciting challenges to psychotherapeutic theory and methodology. Definitive indications and contraindications for its use may not yet be stated.

Since the appearance in 1956 of Eisenstein's Neurotic Interaction in Marriage, ${ }^{11}$ publication of papers and books on the treatment of family and marriage problems has mounted. While for many years social workers and others have done "marriage counseling," psychiatrists only recently have started to work actively in this field, or at least to report their work in publication (Grotjahn ${ }^{19}$ pp. 90-104). The impact of psychoanalytic theory and practice on the concepts and techniques of psychotherapy tended to focus on the treatment of individual patients and has aimed at altering intrapsychic as well as external adaptation through manipulation of the psychological process. This has brought excellent therapeutic results in ccrtain categories of patients, but many others have not been treated or their treatment has failed. Frequently this has been accounted for by judging them as "untreatable," or by deciding that the psychotherapeutic method was poorly applied. It appears that many of these conclusions were arrived at largely by assumption, since there is not only little objective data to support such a vicw, but also as increasing evidence to the contrary. $\dagger$ Clearly, adaptive potential and versatility seem to be consistently under-

\footnotetext{
* Presented at the 1962 Annual Meeting; accepted for publication, June 28, 1962.

"For example, studies of the placebo effect demonstrate that even very "sick" psychotics have considerable capacity to improve with nothing more than the increased attention paid them in the context of research operations (Frank, ${ }^{13}$ pp. 65-74).
} 
estimated by professionals.* Likewise, the literature reveals that there is good reason to search further for causes of family disruption using the psychodynamic concept of homeostasis as a launching point (Bell, ${ }^{5}$ pp. 4-5, 48-52; Jackson, ${ }^{22}$ pp. 122-141; and Bowen, ${ }^{7}$ pp. 40-60). In this paper, I will endeavor to explain and conceptualize my recent treatment efforts with family and marriage problems.

Several specific premises regarding the nature of marital unions will be utilized but not explicitly substantiated here. They are:

1. That marriage partners choose each other for highly specific, conscious and unconscious reasons. This selection represents the summation and gratification of normal and appropriate goals, as well as various neurotic and symbolic needs that must be met either intrapsychically or socially (Ackerman, ${ }^{1}$ pp. 148-149; Bell, ${ }^{5}$ pp. $4-5,48-52$; and Sherman ${ }^{30}$ ).

2. Both partners enter into a mutually "satisfying" interlocking homeostatic balance (Basamania, ${ }^{4}$ p. 22, and Jackson, ${ }^{22}$ pp. 129-145). Despite external appearances to the contrary, they reach a state of psychological equilibrium that "gratifies" both mature and neurotic needs for both partners. ${ }^{25}$ One of the treatment objectives in this kind of therapy will be to elucidate the details of this interlocking system, in order to open up the possibility for a different and more appropriate adjustment between them.

3. This homeostatic relationship may also be viewed as a mutually shared communication system involving many verbal as well as nonverbal communica- tion devices. ${ }^{14,24}$ Therefore much characterological interchange will take place, and this will lead inevitably to the necessity for emphasizing the interpretation of character manifestations in this form of treatment. $\dagger$

4. Any therapeutic disruption in the psychological homeostasis of one partner in the marriage will inevitably force upon all other members in the family an alteration in their psychological adjustments. For this reason, it appears that often the most efficient way to impinge upon the interlocking adjustment of the partners is to have both participate in the insight-producing process. This would simultaneously tend to bring about revised homeostatic techniques for each. The family anxiety level may be kept closer to optimal limits than often occurs when individuals are treated separately and only one member has opportunity for, and access to, insightproducing experience (Ackerman, ${ }^{2}$ pp. 61-64).

These, then, are the premises on which this form of treatment is based. In addition, all the basic hypotheses of psychodynamic theory are utilized and woven into the treatment situation.

\section{TECHNIQUE}

There have been several recent papers describing the treatment of marriage partners in various kinds of combinations and with various goals. For example, Ackerman" (Ch. 19) used "interpretive family treatment," while Hambidge ${ }^{20}$ used "simultaneous analysis of marriage partners" to designate such procedures. Greene $^{17}$ describes "concurrent analysis," and Martin and Bird" describe "concurrent psychotherapy," but in neither

\footnotetext{
* See the work of Berlien on military adjustment. ${ }^{\circ}$

† As Reich puts it, how material is stated is as important as what is said, and is the focus for interpreting character defenses. ${ }^{23}$
} 
case are both partners present at the same time. Geist and Gerber, ${ }^{16}$ as caseworkers shying away from the word "therapy," call their technique "joint interviewing," as does Sherman. ${ }^{31}$ Carroll" (pp. 57-62) employs "family unit therapy."

Since none of these adequately designated an insight-producing psychotherapy focused on interpretation of transferences and carried on by a single therapist with both partners simultaneously present, I sought a new designation.

The meanings of the word "conjoint" seemed to satisfy the above requirement. No sooner had the expression "conjoint treatment of marital partners" been coined, when the excellent paper, "Conjoint Family Treatment," by Jackson and Weakland ${ }^{2: 3}$ appeared in print. Correspondence with Jackson revealed that this term had been used in an earlier paper $^{22}$ (pp. 122), which I had not yet secn.

In conjoint psychotherapy, both marriage partners are seen together and the strategic goal of the interpretive process is to work through the central neurotic distortions of their interlocking adaptive and communication systems. This involves interpretation of the multiple transferences, utilizing all the traditional psychoanalytic concepts of personality dynamics. Because of the more complex transaction in these sessions, several specific procedures are followed.

It will be clear to all sophisticated in the theory of psychotherapy that there is an extremely complex interlocking system of transference-countertransference operations present in a therapeutic setting where three individuals participate. Because of this fact, it is essential at the very beginning of treatment to under- stand thoroughly the characteristics and etiology of each partner's psychological participation.

When the decision has been made to treat a couple conjointly, both parties will be interviewed separately for two or three sessions in order to obtain a thorough anamnesis and diagnostic formulation. Following the suggestion of Saul, ${ }^{-9}$ an effort is made to isolate and formulate the core psychodynamic forces operating in each spouse and relate them to precise etiological data. Early memories are obtained; family backgrounds are explored with emphasis on recollections and thoughts about significant family members; dreams and other specific historical details needed to develop the diagnostic formulation are collected. By the time these interviews are concluded, the therapist should be able to make at least a well-educated guess about the meaning of the various communications that will be present during the course of treatment. Just as the significance of communications becomes more clear as individual psychotherapy progresses, so they will become more meaningful in the course of conjoint treatment.

Some may leap to the assumption that patients in this kind of treatment setting will not talk freely about the details of their fantasy life, but this has not proved true. It is my impression that freedom to communicate in such treatment is more often than not a function of the therapist's comfort and countertransference than it is of the patient's inhibition. As Ackerman" has stated (p. ix), "These socalled secrets turn out not to be real secrets at all. Far more often they are common family knowledge surrounded by a tacit conspiracy of silence." I share this view, and, when the basis for the 
conspiracy is worked through, the participants have no further need to avoid free discussion, or free association.

As the exploratory sessions with each partner are drawing to a close, it is usually in order to make some general statement to each about specific adaptive techniques that appear to create their difficulty. Then, when both are brought back into the conjoint setting, they will have some anticipation about their own contribution to the marriage problems.

As in all psychotherapy, conjoint treatment starts where the patients want it to start. They may or may not talk about themselves, their children or a multitude of other problems. Material is not judged "good" or "bad" but as communication relating to the significant problems or resistances. Associations are interpreted in the same way as they are in any other form of psychotherapy. However, one factor controls the interpretive choice made at any given time: All interpretations will focus on those aspects of the material and dynamics that relate to the process of communication between the spouses. In other words, in selecting which of several alternative interpretations to make, the therapist will choose the one that is related dynamically to the cause of the communication distortion in the marriage. Material mainly relevant to only one partner will not be interpreted.*

As material is brought up by one or the other partner and its meaning is interpreted in the presence of both, it helps the listening or observing spouse to impersonalize communications and progressively see them as a function of his partner's psychic problem. This dis- tance-producing measure facilitates improvement in the ego's perceptive capacity, progressively decreases the narcissistic identifications between the partners, and thereby improves their capacity to communicate rationally and resolve mutual problems more objectively. For example, if psychological closeness is ego-threatening to a husband, any demonstration of closeness and intimacy by his wife will cause him to withdraw and she will usually interpret this as personal rejection. When this maneuver manifests itself and is interpreted in treatment, the husband can learn to understand why he "needs" to withdraw. At the same time, the wife is learning why she views such reactions as personal and, progressively, how to objectify the meaning of the withdrawal.

Another important aspect of this technique is that the therapist must obscrve strict strategic neutrality. He will interpret objectively whatever he sces in the behavior of both spouses, and from time to time will focus his attention on one more than the other. Over the course of treatment, however, he will not ally with one party more than with the other. This is especially important in the beginning phases of treatment, and it is essential to establish this fact clearly to both participants. For the first several hours, this necessitates shifting interpretive focus back and forth between the partners, so that hours end with each recciving approximately equal attention from the therapist. Interpretation should also balance in terms of their positive and negative implications to the partners.

After setting forth to both partners the psychological premises stated above,

* This focus is concurred in by Bell ${ }^{5}$ (pp. 4-5), Carroll ${ }^{\circ}$ (p. 60), Ackerman² (pp. 65-66), Jackson et al. ${ }^{39}$ (pp. 36-38) and others. 
the therapist then encourages the unfolding of the marital problems. Usually this happens quickly and in very vivid form. As in all transference-oriented treatment, it is possible to see at first hand the nature of the psychological participation of both partners. The therapist need not speculate about what has happened at home, since he may directly observe the interaction between them, as well as their individual transferences to him. Especially in the early phases of treatment, this is excellent material to focus upon, since it gives patients insight into the goals of treatment, provides them with sufficient gratification to offset some of the anxiety this technique produces, and thereby creates "hope" that the treatment will be worthwhile. ${ }^{27}$ Such an attitude is a crucial element for effective therapy (Carroll, ${ }^{9}$ p. 59; Chance, ${ }^{10}$ pp. 151-154).

One of the principal tactical advantages of this kind of treatment lies in the fact that it is possible to make an interpretation to one spouse, though its main impact is directed toward the other one. If there is strong resistance or ego vulnerability in one, a correlated interpretation can be made to the other spouse, thus turning the interlocking nature of the marital neurosis to therapeutic advantage. For example, if there is a provocative-masochistic tendency in one, coupled with sadistic-criticalness in the other, cither side of this emotional axis may be interpreted. Both hear the interpretation and perceive it in terms of their own dynamics. If they have a psychological need to do so, they may, temporarily at least, be permitted to view this as "the other person's problem." Such displacement-potential is useful for regulating the timing of interpretations, while permitting the therapist to deal with current pertinent material. This considerably increases therapeutic flexibility.

This approach stirs up active psychological participation in the couple, with mounting anxiety usually related closely to the emotional stalemate that brought them to therapy. It is important to give reassurance during the early stages, while they are in the process of discovering their own powers to sustain such discomfort. The therapist, during his early experience with this form of treatment, will likewise reverberate to the patient's anxiety, until he too finds that it is possible to carry out and control such therapy. Ultimately, his calmness and comfort in participating in this process, more than anything else, provides patients with the will to explore and accept what had been frightening in the past and had always caused avoidance and reinforced repression ${ }^{7}$ (p. 56).

Another characteristic of this technique is the degree of participation in the process by the therapist. In most one-to-one psychotherapy, the therapist can remain essentially passive, only occasionally making interpretive or confronting remarks. In conjoint treatment, where interpretation often centers upon some character manifestation, the "action" is fast-moving and the therapist will by necessity bring himself more into view (Ackerman,, pp. 63-64; Jackson,, ${ }^{23}$ pp. 38-39). Also, as interpretations are made, he may "lend" his identity by way of references to personal experiences that serve to underscore his awareness of the problems as well as his belief that they may be resolved. This can be analogized to the ego support rendered by parents to their children as they encourage the annexational identifications that press them forward in their exploration and mastery of reality. Though this 
kind of support is more specific and tangible in conjoint treatment, it is certainly present at least by implication in the most classical psychoanalytic process. In fact, one might say that one of the criteria for psychoanalysis is the capacity on the part of the patient to perceive this fact. If patients cannot, some alternative approach must be taken. ${ }^{12}$

From the supervisory observation of residents utilizing this kind of therapy, it is clear that there are many "styles" in which it can be conducted. However, in comparison with other forms of therapy carried out by the same resident, there is likely to be much more activity exhibited in conjoint treatment. Needless to say, this has countertransference implications. For example, it has been stated that many who practice psychotherapy do so in order to participate vicariously in the emotional life of others. ${ }^{32,33}$ The essentially passive relationship of the therapist to his patient in most kinds of psychotherapy permits such participation while retaining relative noninvolvement. To whatever degree this need is present in a given therapist, he will be strongly disinclined to utilize such procedures as conjoint therapy. The corollary probably is also true, that the more actively inclined will find this method holds special attraction. (In assaying any psychotherapeutic process, it is obviously important to take into account the therapist's conscious and unconscious attitudes about "how" and "what" therapy "will work" (Frank, ${ }^{13}$ pp. 114-141).

Once this treatment technique has been elected, it should be the dominant therapeutic mode, at least until the interlocking psychological problems of the couple have been resolved. However, on occasion one spouse may try to use the therapeutic situation to act out neurotically, in a way that would create individual problems and disrupt the timing of the therapeutic process. Such maneuvers should be blocked promptly by the therapist through interpretation. If such acting out cannot be checked within the conjoint sessions, there is reason to see that spouse individually sufficiently often (usually one to three sessions) to clarify and obviate the motives for such masochistic moves. Any reactions stirred up in the partner not seen alone must be dealt with actively, and occasionally he, or she, too must be seen alone in order to retain balance.

After the conjoint sessions have been reinstituted, the material that came out in the individual meetings can usually be worked slowly into the discussions. Sometimes these separate sessions turn out to have been flanking moves to avoid a conjoint issue. In such a case it must be so interpreted to the partners, and the therapist should view the separation as a tactical miscalculation.* At other times enormously valuable material emerges which, when dealt with conjointly, moves therapy forward precipitously because of the therapist's deepened understanding and the patients' added insight.

\section{TECHNICAL PROBLEMS}

The main problems arising in conjoint treatment are the product of the more complex transference-countertransference reactions. Clearly, conjoint therapy should not be undertaken unless the therapist can comprehend quickly what is going on in the sessions and can think freely about the material in precise

\footnotetext{
* Some therapists such as Bell ${ }^{5}$ (pp. 24-28) would refuse altogether to see one family member
} alone. This has not been a problem in our work. 
psychodynamic terms. So much occurs during the conjoint sessions that the therapist has no time to pause and reflect at length before dealing with the material. Neither can he sit by and wait for multiple confirmations of the psychodynamic theme before he decides to make an interpretation. To do so puts him far behind the affectively significant events, and he may never come abreast of the significant transactions. While there will be much reiteration of material, the same timing problem will always exist.

Obviously there are two sets of transferences, as well as two sets of countertransferences (I say "sets" deliberately, to reflect the overdetermined imago present in any individual's repetition-compulsion). Because of the presence of both marital partners and the more realistic presentation of problems, there is an increased risk of the therapist's unconsciously identifying with one or the other spouse. However, by being aware of this hazard and through more active involvement in the therapeutic process, there is greater opportunity for empathic identification and a quicker grasp of the problems unfolding before and with him. Under these circumstances it is neither possible nor effective to have long periods of silence nor to avoid finding answers to specific reality problems. This does not mean that the goal is simply to gratify. Rather, the exploration for answers is carried on in a way that impinges dynamically on the neurotic process of the couple. The act of mutual exploration is contrived to clarify the defensive maneuvers of each spouse in such a way as to increase insight and maturation even as a problem is being solved ${ }^{19}$ (pp. 100-101). Obviously this is different from the kind of communication used in more typical psychotherapeutic interpretation. It appears, how- ever, that its dynamic effect is similar. Defensive distortions are forced into sight where their current implications can be subjected to reality testing and possible revision.

Another common countertransference anxiety in conjoint treatment arises when the partners begin to make threatening remarks about getting a divorce, or some other offer to act out. Because both partners are present to witness the intense affect unleashed, and because it may readily be interpreted as more than mere transference, the therapist is likely to wonder if he may not have a tiger by the tail. These occasions may be turned to good therapeutic advantage, but only if the therapist is comfortable in taking them up and working them through. He may very easily assume that he has been the cause of such an upset. While this is obviously not true, the physical presence of both partners with their emotional reactions to the therapeutic situation makes this distortion easy to believe.

The therapist is also likely to react with deep concern to other kinds of highly charged material as it emerges and creates the specter of serious trouble between the partners. As noted above, such material is not truly secret, and its revelation presents an opportunity to clarify issues that have too long been hidden just deeply enough to prevent resolution and yet cause marriage difficulties. To date, there have been no instances in which truly damaging material has arisen. Rather, it has been confirmed that the information was "known" by both parties beforehand.

\section{TECHNICAL ADVANTAGES}

Though it is often stated that the psychotherapist presents no value judgments to his patients, I do not accept 
this view. For example, whenever it is decided that there has been a neurotic distortion such as projection, a value judgment about reality has been made and, along with it, an estimate of the degree of distortion..$^{15}$ All this is inferred from what the patient has said, which places a large analytical task upon the therapist. Though he does have access to transference reactions with which to check out impressions of extra-therapy behavior, there is always the possibility of error due to observational bias, as well as the likelihood that some reactions to the therapist will be different in kind from those to other persons in the environment. In conjoint therapy there is the immediate advantage of direct observation of the participants in the family problem. This facilitates more objective evaluation of the partners' behavior and limits the need to judge distortion from more indirect data. This frees the therapist's energy to deal with the complexity of the process, and well offsets the disadvantages arising from the increased distortion potential caused by the complicated interaction.

Another marked advantage of this technique results from the pressure it places on the couple to re-examine their reality testing. When an interpretation is made to one spouse, the other has the opportunity to hear it, remember it, and reintroduce it, during the interim between therapeutic sessions. This provides the therapist with a working assistant for each of the partners, who will constantly reinforce the interpretation he makes during therapy sessions. While there is a possibility and even a probability that interpretations will be used for nontherapeutic purposes, the general summation effect is reinforcement of, and mounting pressure toward, increased reality testing by both spouses. In most individual psychotherapy there is a strong tendency for the patient to leave the hour and fall back into archaic patterns of problem solving and old ego defenses. Ever so slowly the therapist breaks into the automaticity of the defense system, to bring about broadening of the reality testing and subsequent improvement in the patient's capacity to synthesize and manipulate current experience. The speed with which conjoint therapy improves reality testing is a distinct advantage. There is, in addition, the marked ego satisfaction that comes from the fact that both spouses are participating jointly in the solution of common problems. Here there is no untreated spouse to build up fantasies of being conspired against by the therapist (Ackerman, ${ }^{2}$ pp. 57, 64; Ackerman," p. $\left.111 ; \mathrm{Brady}^{8}\right)$. Instead, there is the clear opportunity to work with the partner and share in the resolution of difficulties. Thus one of the principal problems in treating a married person may be avoided.

Another advantage in conjoint treatment is that insights are gained in the very context from which problems arise. This removes much of the need to translate from transference back to reality, since reality and transference are close together in time and content and therefore more accessible to perception and learning. Such contextual analysis appears to enhance markedly the speed of such learning, even while maintaining the advantages of individual treatment to ferret out and clarify neurotic distortions. This avoids vicarious guilt in one partner for gaining something the other is not getting, and facilitates the forging of a new ego ideal that can be held jointly by both ${ }^{3}$ (pp. 115-116).

The final advantage I would like to comment on is economic. There is ample 
evidence that the decision of who gets psychotherapy depends to a large extent on economic status (Chance ${ }^{10} \mathrm{Ch}$. 7; Hollingshead and Redlich $\left.{ }^{21}\right)$. Obviously, if the multiple parties to a marriage problem may be successfully and simultaneously treated, the saving of professional time will have at least two immediate and practical reverberations for this group of patients:

1. Therapy will become at least twice as available, which is important in the face of an absolute shortage of treatment personnel.

2. The cost of treatment to such a couple may be halved, which can extend the availability of treatment to many who cannot now afford it.

There are other economic effects in conjoint treatment. Several writers have commented on the speed with which this process works, and I concur fully with such observations (Bell, ${ }^{5}$ pp. 49-50; Bowen, ${ }^{7}$ pp. 57-58). Psychodynamic elements that ordinarily take months to raise to awareness sufficient for their being re-examined and reality tested emerge and are effectively altered in a matter of four or five sessions. While these new insights are not fully integrated in such a short time, the improved adaptation that re-evaluation of attitudes and feelings carries with it begins and gains momentum. Patients can then return to their own reality testing and experience gathering with a likelihood for continued maturation. * This accelerated process, if the passage of time demonstrates that gains are maintained, will result in much saving of expensive professional time as well as many direct and indirect economic and social gains for patients.

\section{INDICATIONS}

To discuss indications for conjoint therapy at length would be premature. However, there are several specific situations in which they seem clear-cut:

1. In those family relationships where the commonly held distortions are so gross and so reality-disruptive that speed in checking family disintegration is a critical factor, conjoint treatment seems to offer an ideal way in which to slow down the destructive neurotic process and provide a chance to resolve at least the surface problems before they destroy the marriage, and often the children.

2. This technique is especially well suited to cases in which the problems are largely of an acting-out, characterological nature. It helps greatly in "trapping" these maneuvers where they can be seen, interpreted and attached to some of the underlying neurotic dynamisms and affects. This makes it very useful in just that type of case in which the parties are "poorly motivated" and "not ready" for treatment. Once they are seen in this therapeutic setting, they may very quickly be led to "discover" reasons and feelings to justify continuing.

Various writers have proposed narrower indications than these, such as the

\footnotetext{
* It seems appropriate here to quote part of a footnote from Freud' ${ }^{14}$ Rat-man case:

"It was impossible to unravel this tissue of phantasy thread by thread; the therapeutic success of the treatment was precisely what stood in the way of this. The patient recovered, and his ordinary life began to assert its claims: there were many tasks before him, which he had already neglected for too long, and which were incompatible with a continuation of the treatment. I am not to be blamed, therefore, for this gap in the analysis. The scientific results of psychoanalysis are at present only a by-product of its therapeutic aims, and for that reason it is often just in those cases where treatment fails that most discoveries are made." (Italics added.)
} 
presence of children, and the absence of psychosis. I myself have not felt these limits to be necessary, and successful treatment has been carried on outside of them.

The question arises as to how far conjoint treatment can be carried. The answer to this is not yet clear, since various cases have proceeded (and are proceeding) to the handling of all levels of psychopathology from superficial to deep. It does appear, however, that when the focus of psychological emphasis shifts away from clements of mutual emotional cathexis to the partners, if further therapy is needed it should move to individual sessions. There is reason to believe that one should not leap too quickly to this alternative, since it is clear that even dreams and fantasies among marriage partners have a high degree of mutuality. These facts seem to indicate that there will be far-reaching therapeutic potential for conjoint psychotherapy.

\section{CONTRAINDICATIONS}

As with the discussion of indications, it is not yet possible to set forth any specific contraindications. Couples have been treated who were grossly psychotic or involved in the weirdest varieties of reality difficulties, as well as more runof-the-mill and superficial problems. If reality is not too far out of hand, it appears possible to utilize this kind of treatment advantagcously. Neither have any situations arisen in which it was felt that this method was "dangerous." The question of contraindication, then, must also remain open until further experience has been accumulated.

\section{SUMMARY}

Conjoint psychotherapy of marriage partners seems to hold promise as a means for therapeutically intervening in many problems that have formerly defied success. The principal bar to utilization may rest more in countertransference problems than it does with difficulties experienced by patients. Its main prerequisite is the capacity to understand psychodynamic events with facility so that therapeutic interventions may be made promptly and in the context of the early appearance of material. To date, a precise statement of indications and contraindications may not be made.

\section{REFERENCES}

1. Ackerman, N. W. 1958. The Psychodynamics of Family Iife. Basic Books, Inc. New York, N.Y.

2. 1961. A dynamic frame for the clinical approach to family conflict. In Exploring the Base for Family Therapy. Family Service Association of America. New York, N.Y.

3. 1959. The psychoanalytic approach to the family. $I / n$ Individual and Familial Dynamics, J. H. Masserman, Ed. Grune \& Stratton, Inc. New York, N.Y.

4. Basamania, B. W. 1961. The emotional life of the family: inferences for social casework. Am. J. Orthopsychiat. 31(1): 74-86.

5. Bell, J. E. 1961. Family Group Therapy. Public Health Monogr. No. 64. U. S. Government Printing Office. Washington, D.C.

6. Berlien, I. C. 1954. Psychiatric aspects of military manpower conservation. J. Amer. Psychiat. Assn. 111(3): 9199.

7. Bowen, M. 1961. Family psychotherapy. Am. J. Orthopsychiat. 31(1): 4060 .

8. Brodey, W. M. 1959. Some family op erations and schizophrenia. Arch. Gen. Psychiat. (Chicago) 1: 388-389.

9. Carroll, E. J. 1960. Treatment of the family as a unit. Penn. Med. J. 63(1): 56-72.

10. Chance, E. 1959. Families in Treatment. Basic Books, Inc. New York, N.Y.

11. Einstein, V. W. 1956. Neurotic Interaction in Marriage. Basic Books, Inc. New York. N.Y. 
12. Erikson, E. 1956. The problem of ego identity. J. Am. Psychoanal. Assn. 4: 91.

13. Frank, J. D. 1961. Persuasion and Healing. Johns Hopkins Press, Inc. Baltimore, Md.

14. Freud, S. 1950. A case of obsessional neurosis. $\quad I n$ Collected Papers, Vol. 3. Hogarth Press. London, Eng. : 345.

15. Friend, M. R. 1960. The historical development of family diagnosis. Soc. Serv. Rev. 34: 11-12.

16. Geist, J. and N. Gerber. 1960. Joint interviewing: a treatment technique with marital partners. Social Casework 41(2): 76-83.

17. Greene, B. L. 1960. Marital disharmony: concurrent analysis of husband and wife. Dis. Nerve. Syst. 21(2): 73-78.

18. Grotjahn, M. 1960. Psychoanalysis and the Family Neurosis. W. W. Norton and Co., Inc. New York, N.Y. Chs. 7, 9 .

19. 1959. Analytic family therapy: a survey of trends in research and practice $I n$ Individual and Familial Dynamics, J. H. Masserman, Ed. Grune \& Stratton, Inc. New York, N.Y.

20. Hambidge, G. The Simultaneous Psychoanalysis of Marriage Partners. Presented at the meeting of the American Psychoanalytic Association, Philadelphia, 1959.

21. Hollingshead, A. B. And F. C. Redlich. 1958. Social Class and Mental Illness. John Wiley \& Sons, Inc. New York, N.Y. 266-267.

22. JACKSON, D. D. 1959. Family interaction, family homeostasis and some implications for conjoint family psychotherapy. In Individual and Familial Dynamics.
Jules H. Masserman, Ed. Grune \& Stratton, Inc. New York, New York.

23. JaCKSON, D. D. AND J. H. WEAKLAND. 1961. Conjoint family treatment. Psychiatry 24 (Suppl. 2.): 30-45.

24. Jackson, D. D., J. Riskin and V. SATIR. 1961. A method of analysis of a family interview. Arch. Gen. Psychiat. 5: 322324.

25. KuBIE, L. S. 1956. Psychoanalysis and marriage. In Neurotic Interaction in Marriage. V. Einstein, Ed. Basic Books, Inc. New York, N.Y. : 10-31.

26. Martin, P. and H. W. Bird. 1959. A marriage pattern: the 'lovesick' wife and the 'cold sick' husband. Psychiatry 22: 246.

27. Menninger, K. 1959. Hope. Am. J. Psychiat. 116: 481-491.

28. REICH, W. 1949. Character Analysis. Orgone Institute Press. New York, N.Y. :45-53.

29. SAUL, L. J. 1957. The psychoanalytic diagnostic interview. Psychoanal. Quart. 26(1): 76-90.

30. Suerman, S. N. 1961. Concept of the family in casework theory. In Exploring the Base for Family Therapy. Family Service Association of America. New York, N.Y. : 22.

31. 1959. Joint interviews in casework practice. Social Work. 4(2): 2028.

32. SzAsz, T. 1956. On the experiences of the analyst in the psychoanalytic situation. J. Am. Psychoanal. Assn. (4): 204-208.

33. Wheelis, A. 1956. The vocational hazards of psychoanalysis. Int. J. Psychoanal. 36: 171-184. 